\title{
International X-ray Analysis Society Launched
}

In August 1998 the Organizing Committee of the Denver $\mathrm{X}$-Ray Conference voted unanimously to help launch a new society that would eventually become the sponsor of its meeting and, potentially, of similar meetings throughout the world. The International X-Ray Analysis Society (IXAS) will be dedicated to materials analysis applications of spectrometry and diffraction.

The objective of the Society will be to serve professionals working in the field of materials analysis by:

- fostering interaction among materials scientists, chemists, physicists, geologists, and others engaged in the use of $\mathrm{X}$-rays and other radiations, including neutrons and electrons, for materials analysis.

- sponsoring meetings of interest to those in the field of materials analysis; and

- disseminating information of interest to the materials analysis community.

Membership in the IXAS will be open to all persons involved in analysis of materials using $X$-rays and other radiations.

Discussions about forming an international society of this type date back to open meetings held at the Pacific International Congress on X-Ray Analytical Methods in 1991, and at a joint Denver X-Ray Conference and IUCr Commission on Powder Diffraction Satellite Meeting held in 1996. Interest in forming such a society varied among individuals, often depending on perceptions of how well their national or multi-national regional meetings were serving their needs. Many were attracted to the idea of a society that concentrates on the applications of materials analysis by $\mathrm{X}$-rays, neutrons and electrons.

A draft Constitution for the IXAS has been prepared, and the next step is the formation of a Steering Committee to guide the Society through its formative stages. The Steering Committee will include the current members of the Denver X-ray Conference Organizing Committee (DXCOC) and 10-15 non-US members. The Committee will represent all areas within the purview of the IXAS: fluorescence, emission, absorption, non-medical imaging, diffraction, etc.

Ron Jenkins, Chair of the DXCOC, will Chair the Steering Committee. It is anticipated that after a period of two years the IXAS will hold its own elections to ensure its ongoing viability. As soon as the Steering Committee is in place a meeting of the committee to discuss the IXAS constitution and operating procedures, cooperating societies, society journal, etc.

Interest has already been expressed in having the IXAS co-sponsor meetings in Europe and Southeast Asia. It is anticipated that membership in the IXAS will be initiated through the registration for such meetings, as well as through conventional applications and dues payments. If you are involved in a meeting that would benefit from co-sponsorship by the IXAS, have a proposal for a new meeting, or just want to be among the founding membership of the Society, please contact me.

G. J. McCarthy, Secretary-Treasurer
IXAS Steering Committee
Department of Chemistry
North Dakota State University
Fargo, ND 58105-5516 USA
gmccarth@prairie.nodak.edu
$701-231-7193$ (phone)
701 231-8831 (fax)

